\title{
A study on the energy dissipation of several different CFRP-based targets completely penetrated by a high velocity projectile
}

PJ Hazell* and G Appleby-Thomas

Cranfield Defence and Security, Cranfield University, Shrivenham, Swindon, Wiltshire, SN6 8LA

\begin{abstract}
The threat of fragmenting munitions from MANPADS to civilian and military aircraft has, in recent years, become an ever increasing worry. One of the ways to enhance the protection of CFRP based composites is to add lightweight materials that can provide increased ballistic protection. In this study, several hybrid CFRP laminates of different material and geometrical configurations have been subjected to a high velocity steel sphere with an impact energy of c.a. $440 \mathrm{~J}$. It was found that 12 layers of ballistic-grade Kevlar $^{\mathrm{TM}}$ loosely bound to the rear of the CFRP laminate proved to be the most weightefficient method of dissipating the kinetic energy of the projectile. Furthermore, the impact response of a non-woven symmetrical CFRP laminate has been compared to that of a woven laminate over an impact-energy regime of $92 \mathrm{~J}$ to $459 \mathrm{~J}$. At lower impactenergies there were strong indications that the non-woven laminate out-performed the woven laminate whereas at the higher impact-energies the ballistic performance was seen to be approximately the same.
\end{abstract}

Keywords: A. Carbon fibre, B. Impact behaviour, C. Ballistic penetration, D. Energy dissipation

Email: p.j.hazell@cranfield.ac.uk

Tel: +44 (0) 1793785731 


\section{INTRODUCTION}

The terrorist threat to civilian airliners in recent years has become all the more problematic due to the proliferation of MANPADS (man-portable air-defence systems). These systems are capable of launching a missile in the general direction of the aircraft and detonating a fragmenting munition at close proximity to the aircraft's structure. Typically, steel or tungsten fragments are propelled towards the aircraft at high velocity. Although there has been considerable effort to develop countermeasures against such missile systems, these have been deemed prohibitively expensive for commercial airliners [1]. Consequently, there is currently no suitable solution that can provide effective protection against high velocity projectiles produced by a fragmenting munition.

One possibility for improving the survivability of passengers and crew in a civilian airliner is to harden the structure. This is problematic at best due to the increase in weight that would be expected from such a process. However if critical subsystems are sufficiently protected, it may be possible to prevent catastrophic failure of the aircraft when an anti-aircraft munition is detonated in close proximity.

For the foreseeable future, carbon fibre materials will be extensively used in aircraft design [2]. Most high-velocity studies with CFRPs to date have been done using single specimens of relatively thin laminates [e.g. 3-13] that offer very little protection against high velocity projectiles. These studies have shown that these materials have very low trans-laminar strengths and provide very little protection against high energy threats such as a fragment from an anti-aircraft munition. Furthermore, there is a growing body of evidence that suggests that the lay-up type and sequence has little effect on the 
performance of a 2D laminate when the material is subjected to a high velocity impact. This appears to be contrary to what has been observed during low velocity impact where woven laminates appear to offer advantages [14-17] and where the stacking sequence has an effect [18]. Hazell et al. [3] have previously reported that small changes in the stacking sequence of a woven laminate had negligible effect on its energy absorbing abilities. Whereas Fujii et al. [4] noted that that there was little difference in the absorbed energy when cross-ply [0/90] laminates were compared to woven laminates. Furthermore, Tanabe et al. [5] also showed no difference in energy absorption between cross-ply and woven laminates. Hammond et al. [7] showed that thin laminates of different quasiisotropic lay-ups did exhibit a difference in energy absorption. However, they noted that the measured difference was small and was well within their experimental error. However, they also pointed out that unidirectional composites were significantly weaker than the other lay-ups. Interestingly, Lopez-Puente et al. [19] have studied the effect of low temperature on the impact response of CFRP laminates. They showed that quasiisotropic tape laminates were less effective in terms of residual damage than woven laminates due to the different flexural behaviour of the plies. However no residual velocity was measured in this instance. They also showed that temperature has no effect on damage extension implying that the energy absorbing characteristics at room temperature are similar to that at lower temperatures experienced by high altitude aircraft.

There does, however, appear to be an effect on the material's energy absorbing ability with changing the type of fibre - particularly on the rear surface of the laminate. Tanabe et al. [5] have shown that small differences in ballistic performance are possible if carbon fibres of different properties are used in the through-thickness of the sample. 
They concluded that high tensile strength fibres should be used on the rear surface of the laminate to maximise energy absorption of the projectile. Similar observations were made by Fujii et al. [4]. They also showed that failure modes were affected by the mechanical properties of the fibre. Laminates with low strength carbon fibres resulted in specimens showing plugging-type fractures.

Lamontagne et al. [20,21] have studied the penetration of CFRP laminates at oblique angles; however, this was done at very high velocities that far exceed the velocities of fragments that would be encountered by an aircraft structure. Here, the main focus was on the response of space-craft structures to high velocity impact. Further high velocity impact studies on CFRP-based space-craft structural materials have been conducted by Ryan et al. [22] and White et al. [23]. In these papers the authors turned their attention to the high velocity impact response of hybrid CFRP laminates consisting of either Kevlar layers or aluminium honeycomb bonded directly to CFRP laminates. It was reported in [23] that the presence of Kevlar-epoxy layers reduced the extent of delamination and increased the impact energy required to induce rear surface damage. Again, in this work, the velocities of impact far exceeded those of interest in this paper. Nevertheless, Kevlar is a composite material that is well known for its ballistic properties as are certain grades of aluminium alloy [24].

Most work to date has concentrated on very thin laminates (c.a. $2 \mathrm{~mm}$ ) comparing the ballistic performance of different quasi-isotropic lay-ups or comparing cross-ply [0/90] with woven laminates. In this work we evaluate the ballistic performance of a relatively thick symmetrical non-woven laminate over an impact energy-regime ranging from $92 \mathrm{~J}$ to $459 \mathrm{~J}$ and compare it to a similar woven laminate subjected to impact by 
similar loading conditions [3]. Further we evaluate the energy dissipation and consequent improvement in ballistic performance by adding Kevlar and aluminium layers to this laminate in an attempt to show how the ballistic performance of these materials can be improved.

\section{EXPERIMENTAL METHODOLOGY}

Materials used

The materials chosen for this study were manufactured using the resin transfer method (RTM). All individual panels were manufactured with Tenax HTS 5361 aero grade fibres and chosen because they are commonly used in the aerospace industry. The lay-up consisted of 10 plys: [0/90, $\pm 45,0 / 90, \pm 45,0 / 90]_{s}$. The thickness of each CFRP panel was $5.30 \mathrm{~mm} \pm 0.05 \mathrm{~mm}$. The resin used was Hexcel RTM 6 cured for 1 hour 40 minutes at $180{ }^{\circ} \mathrm{C}$ and at a pressure of $90 \mathrm{psi}$. The dynamic behaviour of the cured resin has previously been studied in [25]. The density of the CFRP material, measured using a Micrometrics AccuPyc 1330 gas pycnometer, was $1.53 \mathrm{~g} / \mathrm{cc} \pm 0.01 \mathrm{~g} / \mathrm{cc}$. The mass fraction of the reinforcement was measured using the acid digestion method according to ASTM D 3171-6, Procedure B [26] and was found to be $70.3 \pm 1.0 \%$.

Two additional materials were also used to construct the hybrid laminates. These were Dural (Al 6061-T6) of thickness $1.02 \mathrm{~mm} \pm 0.01 \mathrm{~mm}$ and plain-weave Kevlar ${ }^{\mathrm{TM}} 29$ fabric manufactured by DuPont (USA) with a yarn linear density of 1500 denier and a 
tow count of 324 tows/square inch. Twelve layers of Kevlar fabric was chosen to match the areal density of the Al6061-T6 $\left(2.8 \mathrm{~kg} / \mathrm{m}^{2}\right)$.

Target construction

The hybrid CFRP laminates were assembled by roughening the surface of each component and applying a two-part epoxy adhesive (Araldite 2015) to bond the layers together under load. Eleven different targets were constructed as summarised in Figure 1 and Table 1. Two different bonding approaches were used for the Kevlar fabric. One set of targets were assembled by just bonding around the periphery of the target (Configurations H, I and J); a target was assembled by completely bonding the surfaces of each respective Kevlar layer to its neighbour (Configuration K).

Figure 1: NEAR HERE.

Impact testing

The projectile used was a fully annealed stainless steel sphere $(\varnothing 11.97 \mathrm{~mm} \pm 0.01$ $\mathrm{mm}$; mass $=7.165 \mathrm{~g} \pm 0.001 \mathrm{~g} ; \mathrm{VHN}=127)$. The balls (AISI 304) were fully annealed in air at $1050^{\circ} \mathrm{C}$ to provide equiaxed austenite grains and consequently isotropic behavior. The yield strength of this steel at $21^{\circ} \mathrm{C}$ is $450 \mathrm{MPa}$ with an ultimate tensile strength of $675 \mathrm{MPa}$ [27]. The projectile was fired from ELVIS, a single stage $\varnothing 22-\mathrm{mm}$ gas-gun. The impact energy ranged from $92 \mathrm{~J}-459 \mathrm{~J}$ corresponding to a velocity range of $160 \mathrm{~m} / \mathrm{s}$ 
to $358 \mathrm{~m} / \mathrm{s}$. This range of velocities is lower than what would be expected from the majority of fragments propelled from an anti-aircraft munition. Nevertheless, anti-aircraft munitions provide a spread of fragments with a distribution of velocities and this velocity range would be representative of some of the propelled fragments. Furthermore, this velocity range is consistent with that of debris that may be propelled from the runway to the underside of an aircraft during take-off and landing [e.g. 28-30]. Target specimens were cut from the bonded panels into $150 \mathrm{~mm} \times 150 \mathrm{~mm}$ squares and secured at the top and bottom using the target holder shown schematically in Figure 2.

Both impact and exit velocities were measured using a high speed video camera (Phantom 7; 20,000 frames per second; $2 \mu$ s exposure time). The energy transferred to the panel was assessed by measuring the impact velocity and the residual velocity of the projectile to an accuracy of $<1 \%$. The energy transferred to the target $\left(E_{t}\right)$ was calculated from

$$
E_{t}=\frac{1}{2} m_{p}\left(v_{i}^{2}-v_{r}^{2}\right)
$$

where $m_{p}$ is the mass of the projectile, and $v_{i}$ and $v_{r}$ are the impact and residual velocities. Consequently, the percentage change in kinetic energy $\left(\Delta E_{f}\right)$ was calculated using

$$
\Delta E_{f}=\frac{E_{t}}{E_{i}} \times 100
$$

where $E_{i}$ is the kinetic energy of the projectile prior to impact. 
Figure 2: NEAR HERE.

\section{RESULTS AND DISCUSSION}

The response of the CFRP laminate alone (Configurations A and B)

The change in the kinetic energy (KE) for the single bare CFRP laminates (without any additional materials) is shown below in Figure 3. Results from similar impact tests on a slightly thicker woven laminate (5HS) from [3] are also included for comparison. In both cases, a rapid drop-off in the percentage of impact energy dissipated by the plate is apparent as the impact energy is increased. Both sets of results show that the percentage of energy dissipated by the laminate appears to approach an asymptotic level. Further studies reported in [12] revealed that the asymptotic level for the 6-mm thick 5HS woven laminate was indeed reached at an impact energy of $2000 \mathrm{~J}$ with a percentage energy absorption of $20 \%$.

In two cases the sphere did not completely penetrate the composite laminate. At an impact energy of $105 \mathrm{~J}$ the sphere became completely embedded, whereas at an impact energy of $92 \mathrm{~J}$ it rebounded, resulting in a lower percentage of energy being dissipated. It is notable that at the higher impact energies (>130 J) this CFRP laminate appeared to perform less-well than the 5HS woven laminate tested in [3]. The slightly poorer performance is, perhaps, expected due to the lower thickness tested here. However, when compared at an impact energy of c.a. $440 \mathrm{~J}$ the percentage of kinetic energy dissipated by 
the laminate, normalised by the thickness, is very similar $(5.4 \% / \mathrm{mm})$. Consequently, these results imply that at the higher impact energies at least, our findings are similar to the findings of Fujii et al. [4] and Tanabe et al. [5]. They showed that there was no difference in the ballistic performance of a laminate regardless of lay-up. However, at an impact energy of c.a. $120 \mathrm{~J}$, the non woven laminate tested dissipated the same amount of kinetic energy as the thicker woven laminate tested in [3]. Indeed, extrapolation of the woven laminate result in Figure 3 suggests that the thinner non-woven laminate performed better than the woven laminate at the lower impact energies. Although the differences do appear small, our results show that there are differences in the energy absorbing ability between the two types of laminates at the lower impact energies with the non woven laminate performing better.

Also included in Figure 3 are two shots that were conducted on the two-part bonded CFRP laminates. At an impact energy of $245 \mathrm{~J}$ (261 m/s), the projectile became fully lodged in the laminate and consequently the system completely absorbed all of the kinetic energy of the projectile. Increasing the impact energy to $436 \mathrm{~J}(349 \mathrm{~m} / \mathrm{s})$ resulted in perforation. Nevertheless, a considerable amount of energy was dissipated by this relatively thick laminate (77 \%). This corresponded to a percentage of impact energy-perunit-thickness of $7.1 \% / \mathrm{mm}$. For this given impact energy (c.a. $440 \mathrm{~J}$ ), this implies that the double-bonded laminates are more efficient at resisting penetration (per unit thickness) than the single laminates. This has been previously been seen with 5HS woven laminate constructions [31].

Figure 3: NEAR HERE. 
The response of the single CFRP laminate that completely stopped the projectile with an impact energy of $105 \mathrm{~J}$ is shown in Figure 4. It should be noted that the highspeed video actually captured a frame every $50 \mu$ s. However, in order to illustrate the nature of the impact a minimum interval of $100 \mu$ s is chosen in this case. Here the reference time ( $0 \mu \mathrm{s})$ is arbitrary and occurs when the projectile is $6.8 \mathrm{~mm}$ from the target face. By $200 \mu$ s, the projectile was completely embedded in the laminate; by $3100 \mu$ s the projectile is completely at rest and ejection of the rear-surface tows is seen. It can be seen that at $100 \mu \mathrm{s}$, the laminate has been subjected to flexure prior to some of the tows being ejected; in this case, only the final layer of tows (running into the paper) are ejected.

Figure 4: NEAR HERE

As shown in Figure 5, increasing the impact energy to $211 \mathrm{~J}(243 \mathrm{~m} / \mathrm{s})$ results in a more catastrophic failure as the projectile completely penetrates the CFRP laminate. There are a few things to note here. Firstly, by $50 \mu$ s penetration of the target has begun and dishing is seen to occur at the rear of the target. Secondly, by $100 \mu$ s failure of the longitudinal tows is seen to occur as the dishing of the rear surface continues before; thirdly, the rear tows break away from the rear surface at $150 \mu \mathrm{s}$. By $250 \mu \mathrm{s}$, the projectile is clearly seen emerging from the target with a kinetic energy of $115 \mathrm{~J}(179 \mathrm{~m} / \mathrm{s})$.

Figure 5: NEAR HERE 
With this composite, the final layers of the carbon fibres appeared to have failed in tension. This behaviour is different from the penetration mechanism of the 6-mm woven RTM composite as seen in [3]. In this case, it was noted that at a higher impact velocity (305 m/s) dishing preceded the formation of a plug of CFRP laminate inferring that a compression / shearing mechanisms had occurred. It should be pointed out that in the course of the study of this particular laminate the formation of a plug of CFRP material was not observed. Previously, other researchers have observed plug formation during the penetration of CFRP materials. Li and Sun [32] noted plug formation in thin CFRP laminates that had been struck by a blunt-ended projectile at relatively low velocities ( $<100 \mathrm{~m} / \mathrm{s})$. Further, Cantwell and Morton [8] have previously shown that during the perforation of a thin CFRP material, a frustum-shaped fracture zone is formed. This observation is consistent with the conically shaped plugs that were soft-captured in [3].

The response of adding aluminium layers (Configurations C-F)

The ballistic performance of the aluminium-based laminates when perforated is summarised in Figure 6. In each case, the impact velocity of the sphere was c.a. $350 \mathrm{~m} / \mathrm{s}$ - the maximum velocity attainable by the gun used in this experimental programme and corresponding to an impact energy of c.a. $438 \mathrm{~J}$. This velocity of impact resulted in a percentage of impact energy dissipated by the bear CFRP laminate of c.a. $30 \%$ which is close to the level of absorption expected from single laminates subjected to much higher impact velocities [12]. Also included in Figure 6 are the level of energy dissipated by both a two-part bonded CFRP laminate and single laminate for comparison. 
Figure 6: NEAR HERE

As can be seen from Figure 6, c.a. $90 \%$ of the projectiles KE was dissipated by the twopart bonded CFRP panel that included a Dural interlayer (configuration C). This out performed the two-part bonded CFRP laminate (shown by the arrow). However, it should be pointed out that although this system appeared relatively efficient, its areal density was considerably higher than the other systems tested (see Table 1).

Placing a single thin layer of Dural on either the front or the rear surface appeared to improve the energy dissipation. The configuration with the aluminium on the rear layer (configuration F) appeared to dissipate slightly more projectile kinetic energy than that of the configuration consisting of the layer on the front (configuration E). This is most probably due to the fact that during penetration, the rear-layered target was able to dish quite considerably before petalling (see Figure 7) and consequently expend further energy in the process (see Figure 8). Combining a Dural layer on the front and rear surfaces of the CFRP laminate led to a percentage of KE absorbed of c.a. $70 \%$.

Consequently the additional percentage energy absorbed was $42 \%$ due to the addition of the two layers when compared to the bare CFRP laminate. This value was similar to the combined benefit of individually adding a front layer (20\%) and a rear layer (23\%) to the CFRP implying that the two-layered system conveyed no additional systemic advantage. That is, its energy absorption ability was not greater than that of the sum of its individual parts. 
Figure 7: NEAR HERE

Figure 8: NEAR HERE

The response of adding Kevlar layers (Configurations G-K)

The effect on the energy dissipation of the projectile by adding the Kevlar layers is shown below in Figure 9. Again, in each case, the impact energy of the sphere was c.a. $440 \mathrm{~J}$.

Figure 9: NEAR HERE

Here, the two-part bonded CFRP laminate with the Kevlar layer in-between (configuration G) outperforms the equivalent aluminium system (configuration C, shown in Figure 6). At this velocity, the system manages to defeat the projectile - completely dissipating its kinetic energy. Adding the loose Kevlar layers to the rear of the CFRP laminate resulted in a considerable improvement in performance of the system over and above the fully bonded layers. Cheeseman and Bogetti [33] have noted that weak fibrematrix adhesion is desirable as this allows for fibre stretching. This results in the ready delamination of the fabric, which allows the fibres to extend to failure and thereby facilitating further energy expenditure. Figure 10 shows selected high speed video footage of the steel sphere striking a CFRP laminate backed by 12 layers of Kevlar (configuration J); the impact energy was $444 \mathrm{~J}$. In this case, the Kevlar fabric is bonded 
around the periphery of the target only. It is evident that extensive deformation of the target is occurring during the penetration resulting in, this case, a relatively high level of energy dissipation. Consequently, our results are consistent with Cheesman and Bogetti’s observation. Attaching layers of Kevlar on the front face of the CFRP resulted in 45\% of the projectile's kinetic energy being dissipated -- similar to the aluminium-faced CFRP. In these cases, the presence of the CFRP laminate behind the reinforcing material probably restricted the degree of deformation or fibre stretching thereby minimising the energy absorption. Indeed, there was little sign of weave disruption close to the impact site of the Kevlar-faced target.

\section{Figure 10: NEAR HERE}

\section{Analysis of the areal densities}

Below in Figure 11 we have plotted a performance map for each of the samples tested in this experimental programme. We have assumed a linear behaviour in the percentage of energy absorbed as the areal density of the CFRP increases from $8.1 \mathrm{~kg} / \mathrm{m}^{2}$ to $16.2 \mathrm{~kg} / \mathrm{m}^{2}$. Consequently, a straight line is plotted through the results for samples A and B. By implication, any results to the right of the line indicate a ballistic performance where the additional material has a detrimental effect on the system's performance (from a weight point-of-view). Conversely, any results to the left of the line show that the additional material provides a benefit to the overall system. There are a few things to note from these results. Firstly, it is notable that, apart from one case, the Kevlar-based targets 
performed considerably better than the aluminium-based targets (configurations C-F). This perhaps, is expected given the known energy absorbing ability of woven aramid fabrics $[33,34]$. There is one notable exception in configuration I where the 12 layers of the Kevlar on the front surface bestow little-to-no advantage over a bare CFRP laminate. Furthermore, rear-faced Kevlar performs better than placing layers on the front and the back - from a weight performance criterion. Secondly, configuration C is the only sample to fall to the right of the straight line. Although we note that the difference is small, the reduced performance of this target can be explained by sandwiching of the Dural inbetween the CFRP laminates. Consequently, dishing (and energy absorption) was inhibited during penetration. Thirdly, the addition of aluminium faces either to one or both faces of the target (configurations D-F) led to only a small increase in ballistic performance of the system when the additional weight was taken into account.

These results show that a significant increase in energy absorbing ability is best achieved by fixing loose woven aramid fibres to the rear of the CFRP laminate.

Figure 11: NEAR HERE

\section{CONCLUSIONS}

A series of high velocity impact tests have been carried out on a symmetrical nonwoven CFRP laminate and a variety of hybrid CFRP sandwich panels. The first objective of this work was to evaluate the ballistic performance of a relatively thick non-woven laminate over an impact energy-regime ranging from $92 \mathrm{~J}$ to $459 \mathrm{~J}$ and compare it to a 
similar woven laminate subjected to impact by similar loading conditions. The second objective of this was work was to evaluate the energy dissipation and quantify the improvement in ballistic performance by adding Kevlar and aluminium layers to the CFRP. This work has shown that:

(1) Although the ballistic performance as measured per-unit-thickness was similar to an RTM-based woven structure at the high impact energies, there are strong indications that at the lower impact energies, the non-woven sample tested here out-performed the woven sample.

(2) Adding 12 layers of ballistic grade Kevlar ${ }^{\mathrm{TM}}$ loosely bound to the rear of the CFRP laminate performed considerably better than other similar weighted configurations including the use of Dural. Indeed we have found that for an impact-energy of c.a. $440 \mathrm{~J}$, $93 \%$ of the projectile’s kinetic energy was dissipated as opposed to $77 \%$ that can be achieved by bonding a second CFRP laminate of equal thickness to the target laminate. (3) Placing layers in-between two CFRP laminates, where the main mechanism of energy absorption is through inelastic deformation due to dishing, results in a reduced ballistic performance when weight is taken into account.

(4) The addition of Kevlar to the front surface of the CFRP laminates resulted in little-tono improvement to the ballistic performance of the system by virtue of the fact that the CFRP laminate appeared to restrict fibre extension.

Overall it is apparent from this study that significant measurable improvements in ballistic performance of CFRP-based structures can be introduced for only c.a. $25 \%$ increase in areal density. 


\section{ACKNOWLEDGEMENTS}

The majority of the experimental work was carried out during Mr Sanjeev Agawal’s Military Vehicle Technology MSc course and consequently we are very grateful for his contribution. We are also very grateful for the experimental support provided by Mr GA Cooper and the helpful discussions with Dr G Kister. The authors would like to thank Mr K Campbell of Short Brothers plc, Belfast, UK for supplying the CFRP panels and Professor I Horsfall (Cranfield University) for supplying the woven Kevlar fabric. We also acknowledge DOSG (UK) who funded the development of ELVIS - the gun used in this experimental programme.

\section{REFERENCES}

1. Bolkcom, C. Homeland Security: Protecting Airliners from Terrorist Missiles. CRS Report for Congress, Order code RL31741, February 16, 2006.

2. Soutis C. Fibre reinforced composite in aircraft construction. Prog Aero Sci 2005; 41:143-151.

3. Hazell PJ, Kister G, Stennett C, Bourque P, Cooper G. Normal and oblique penetration of woven CFRP laminates by a high velocity steel sphere. Compos Part A-Appl S 2008; 39:866-874.

4. Fujii K, Aoki M, Kiuchi N, Yasuda E and Tanabe Y, Impact perforation behavior of CFRPs using high-velocity steel sphere. Int J Impact Eng 2002;27:497-508. 
5. Tanabe Y, Aoki M, Fujii K, Kasano H, Yasuda E. Fracture behavior of CFRPs impacted by relatively high-velocity steel sphere. Int J Impact Engng 2003; 28: 627642.

6. Tanabe Y, Aoki M. Stress and strain measurements in carbon-related materials impacted by high-velocity steel spheres. Int J Impact Engng 2003;28:1045-1059.

7. Hammond RI, Proud WG, Goldrein HT, Field JE. High-resolution optical study of the impact of carbon-fibre reinforced polymers with different lay-ups. Int J impact Engng 2004;30:69-86.

8. Cantwell WJ and Morton J. Impact perforation of carbon fibre reinforced plastics. Compos Sci Tech 1990;38:119-141.

9. Cantwell WJ and Morton J. Comparison of the low and high velocity impact response of CFRP. Compos 1989;20(6): 545-551.

10. Hosur MV, Vaidya UK, Ulven C and Jeelani S, Performance of stitched/unstitched woven carbon/epoxy composites under high velocity impact loading, Compos Struct 2004;64:455-466.

11. Lopez-Puente J, Zaera R and Navarro C, Experimental and numerical analysis of normal and oblique ballistic impacts on thin carbon/epoxy woven laminates, Compos Part A-Appl S. 2008;39:374-387.

12. Hazell PJ, Cowie A, Stennett C, Cooper G. Penetration of a woven CFRP laminate by a high velocity steel sphere impacting at velocities of up to $1875 \mathrm{~m} / \mathrm{s}$. Int J Impact Engng 2009, doi:10.1016/j.ijimpeng.2008.12.001. 
13. Bland PW and Dear JP, Observations on the impact behaviour of carbon-fibre reinforced polymers for the qualitative validation of models, Compos Part A-Appl S. 2001;32:1217-1227.

14. Kim JK, Sham ML, Impact and delamination failure of woven-fabric composites, Compos Sci Tech 2000; 60 (5):745-761.

15. Sanchez-Saez S, Barbero E, Zaera R, Navarro C. Compression after impact of thin composite laminates. Compos Sci Tech 2005;65(13):1911-1919.

16. Curtis PT, Bishop SM. An assessment of the potential of woven carbon fibrereinforced plastics for high performance applications. Compos 1984; 15 (4): 259-265.

17. Cantwell W, Curtis P, Morton J. Post impact fatigue performance of carbon fibre laminates with non-woven and mixed-woven layers. Compos 1983; 14 (3): 301-305.

18. Cantwell WJ and Morton J. The impact response of composite materials - a review. Compos 1991;22 (5): 347-361.

19. Lopez-Puente J, Zaera R, Navarro C. The effect of low temperature on the intermediate and high velocity impact response of CFRPs. Compos Part B-Eng 2002; 33:559-566.

20. Lamontagne CG, Manuelpillai GN, Taylor EA and Tennyson RC, Normal and oblique hypervelocity impacts on carbon fiber composites, Int J Impact Eng 1999;23:519-532.

21. Lamontagne CG, Manuelpillai GN, Kerr JH, Taylor EA,Tennyson RC and Burchell MJ, Projectiles density, impact angle and energy effects on hypervelocity impact damage to carbon fiber/peek composites, Int J Impact Eng 2001;26:381-398. 
22. Ryan S, Schaefer F, Riedel W. Numerical simulation of hypervelocity impact on CFRP/Al HC SP spacecraft structures causing penetration and fragment ejection. Int J Impact Engng 2006;33:703-712.

23. White DM, Taylor EA, Clegg RA. Numerical Simulation and Experimental Characterisation of Direct Hypervelocity Impact on a Spacecraft Hybrid Carbon Fibre/Kevlar Composite Structure. Int J Impact Engng 2003;29:779-790.

24. Børvik T, Clausen AH, Hopperstad OS, Langseth M. Perforation of AA5083-H116 aluminium plates with conical-nose steel projectiles — experimental study. Int J of Impact Engng 2004; 30 (4):367-384.

25. Hazell PJ, Stennett C, Cooper G. The shock and release behaviour of an aerospacegrade cured aromatic amine epoxy resin. Polymer Composites 2008; 29 (10): 11061110. DOI: 10.1002/pc.20614.

26. ASTM Standard D 3171-06. Standard Test Methods for Constituent Content of Composite Materials. ASTM International, 2006.

27. Cryogenic materials data handbook, Volume 1, Sections A-C, Air Force Materials Laboratory, Air Force Command, Wright-Patterson Air Force Base, Ohio, AFMLTDR-64-280, 1970.

28. Martinez CM, Eylon D, Nicholas T, Thompson SR, Ruschau JJ, Birkbeck J, Porter WJ. Effects of ballistic impact damage on fatigue crack initiation in Ti-6Al-4V simulated engine blades. Materials Science and Engineering A 2002; 325,1-2: 465477.

29. Peters JO, Ritchie RO. Foreign-object damage and high-cycle fatigue: role of microstructure in Ti-6Al-4V, International Journal of Fatigue 2001; 23:413-421. 
30. Mines RAW, McKown S, Birch RS. Impact of aircraft rubber tyre fragments on aluminium alloy plates: I-Experimental. Int. J. Impact Engng 2007; 34: 627-646.

31. P Bourque, Characterisation of the effects of ballistic impact on carbon fibre reinforced composites. No 35 Military Vehicle Technology course, MSc Project Report, Cranfield University, Defence College of Management and Technology, July 2007.

32. Lee S-WR, Sun CT. Dynamic penetration of graphite/epoxy laminates impacted by a blunt-ended projectile. Compos Sci Tech 1993;49:369-380.

33. Cheeseman BA, Bogetti TA, Ballistic impact into fabric and compliant composite laminates. Compos Struct 2003; 61:161-173.

34. Karahan M, Kus, A, Eren R. An investigation into ballistic performance and energy absorption capabilities of woven aramid fabrics. Int J Impact Engng 2008; 35 (6):499510. 


\section{FIGURE CAPTIONS}

Figure 1: Target construction.

Figure 2: Experimental set-up for the high velocity shots.

Figure 3: Percentage change in KE due to the perforation of the CFRP laminate at different impact energies.

Figure 4: Selected high-speed video frames showing the impact of a $12 \mathrm{~mm}$ steel sphere on the 5.3-mm thick CFRP laminate (configuration A) at $171 \mathrm{~m} / \mathrm{s}$ (105 J); the circle shows projectile capture.

Figure 5: Selected high-speed video frames showing the impact of a $12 \mathrm{~mm}$ steel sphere on a 5.3-mm thick CFRP laminate (configuration A); impact energy = $211 \mathrm{~J}(243 \mathrm{~m} / \mathrm{s}$ ).

Figure 6: Energy dissipated by the aluminium-based CFRP laminates.

Figure 7: Selected high-speed video frames showing the impact of a $12 \mathrm{~mm}$ steel sphere on a 5.3-mm thick CFRP backed by $1 \mathrm{~mm}$ of Dural (configuration F); impact energy = $448 \mathrm{~J}(354 \mathrm{~m} / \mathrm{s})$.

Figure 8: Rear Dural layer from an experiment (configuration E) showing evidence of dishing and petalling.

Figure 9: Energy dissipated by the Kevlar-based laminates.

Figure 10: Selected high-speed video frames showing the impact of a $12 \mathrm{~mm}$ steel sphere on a $6 \mathrm{~mm}$ thick CFRP backed by 12 layers of Kevlar (configuration J); impact energy = $444 \mathrm{~J}(352 \mathrm{~m} / \mathrm{s})$.

Figure 11: Performance graph for each of the specimens tested in this experimental programme; in each case the impact energy was c.a. $440 \mathrm{~J}$. 
Table 1: Target construction summary

\begin{tabular}{|l|l|l|}
\hline \multirow{2}{*}{ Configuration } & \multicolumn{1}{|c|}{ Description } & \multicolumn{1}{|c|}{$\left(\mathrm{kg} / \mathrm{m}^{2}\right)$} \\
\hline A & A single CFRP laminate & 8.1 \\
\hline B & Two CFRP layers bonded together & 16.2 \\
\hline C & A Dural layer sandwiched in-between two CFRP layers & 19.0 \\
\hline E & CFRP sandwiched in-between two Dural layers & 13.7 \\
\hline F & Dural (impact face) bonded to CFRP & 10.9 \\
\hline G & CFRP (impact face) bonded to Dural & 10.9 \\
\hline H & $\begin{array}{l}\text { A Kevlar lay-up sandwiched in-between two CFRP } \\
\text { layers }\end{array}$ & 19.0 \\
\hline I & $\begin{array}{l}\text { CFRP sandwiched in-between two Kevlar layups (bond } \\
\text { around the periphery of the target) }\end{array}$ & 13.7 \\
\hline & Kevlar (impact face) bonded to CFRP (bond around the & 10.9 \\
\hline & Coriphery of the target) & 10.9 \\
\hline
\end{tabular}




\section{Ø CFRP}

Dural or Kevlar ${ }^{\mathrm{TM}}$

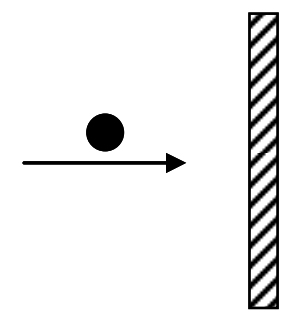

Configuration: A

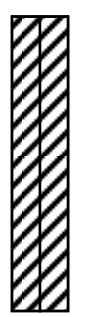

B

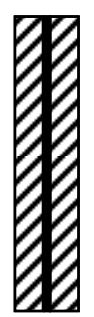

$\mathrm{C} / \mathrm{G}$
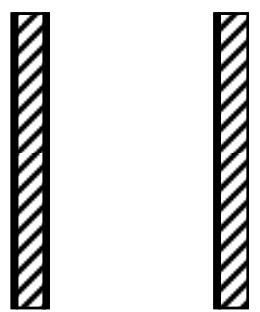

$\mathrm{D} / \mathrm{H}$

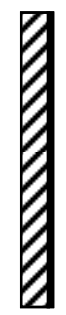

$\mathrm{F} / \mathrm{J} / \mathrm{K}$

Figure 1 
CFRP hybrid laminate target

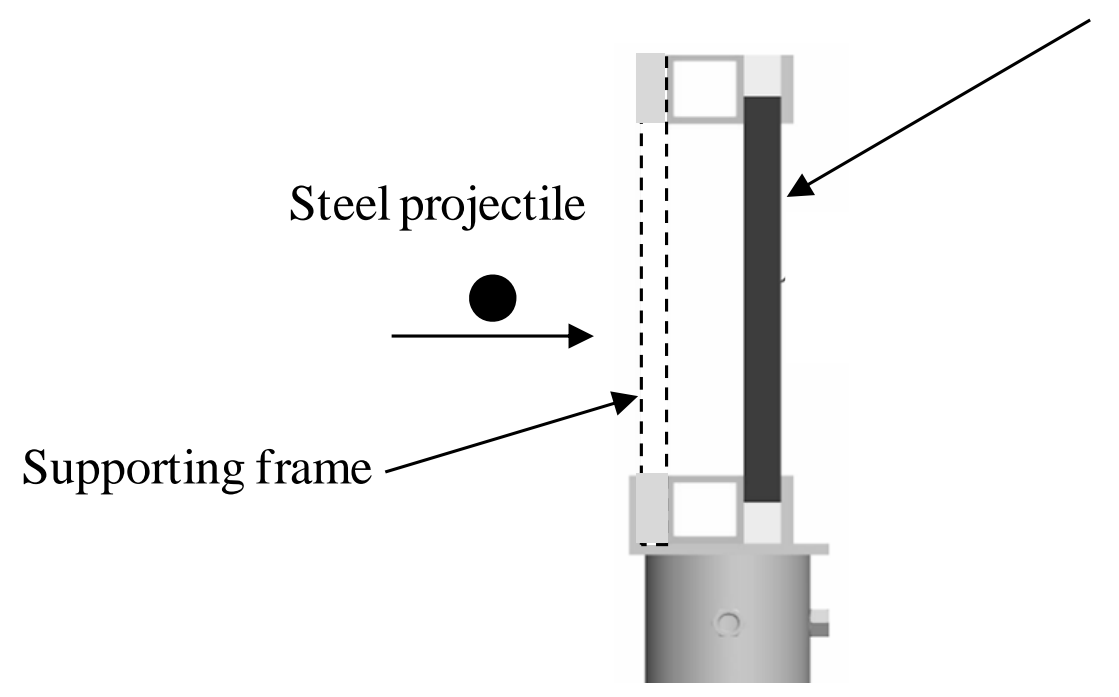

Figure 2 
Composite Structures 91 (2009) 103-109

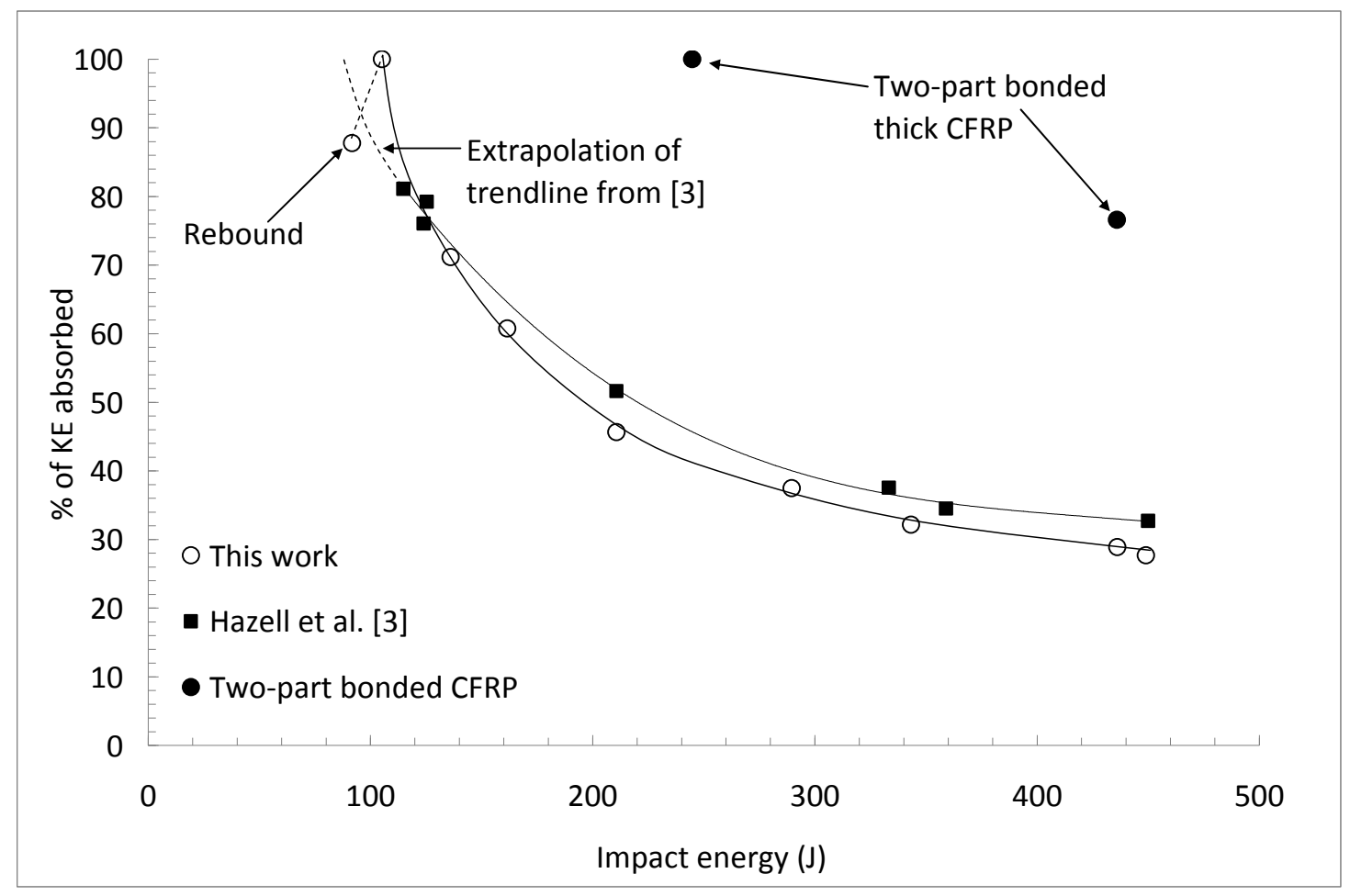

Figure 3 
Composite Structures 91 (2009) 103-109
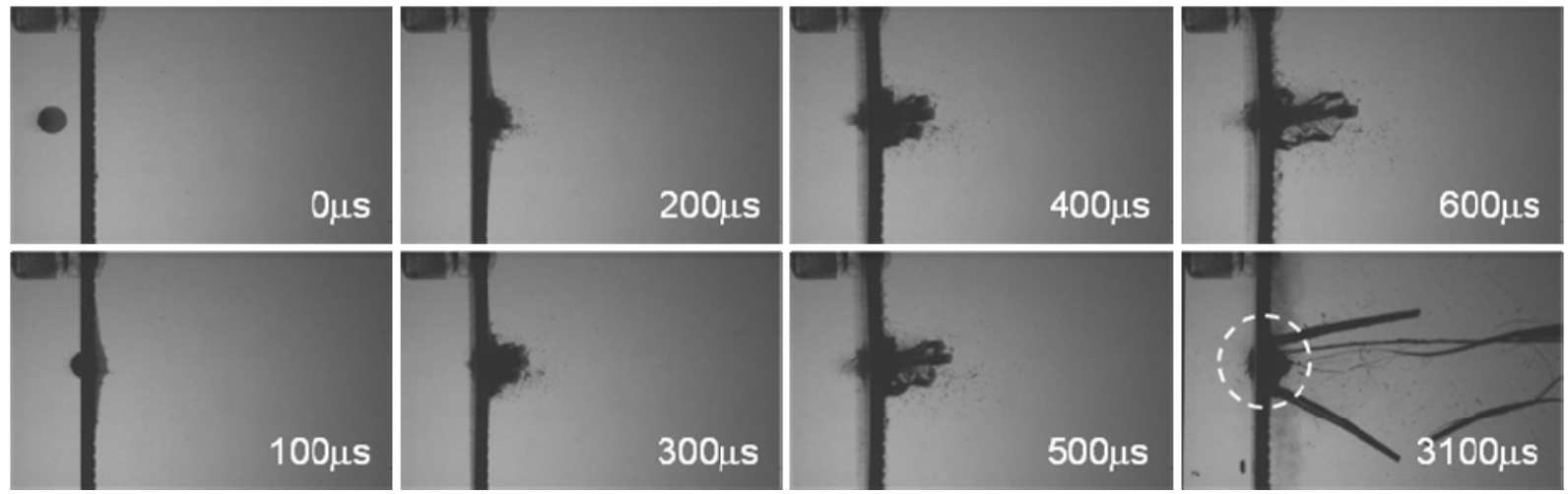

Figure 4 
Composite Structures 91 (2009) 103-109
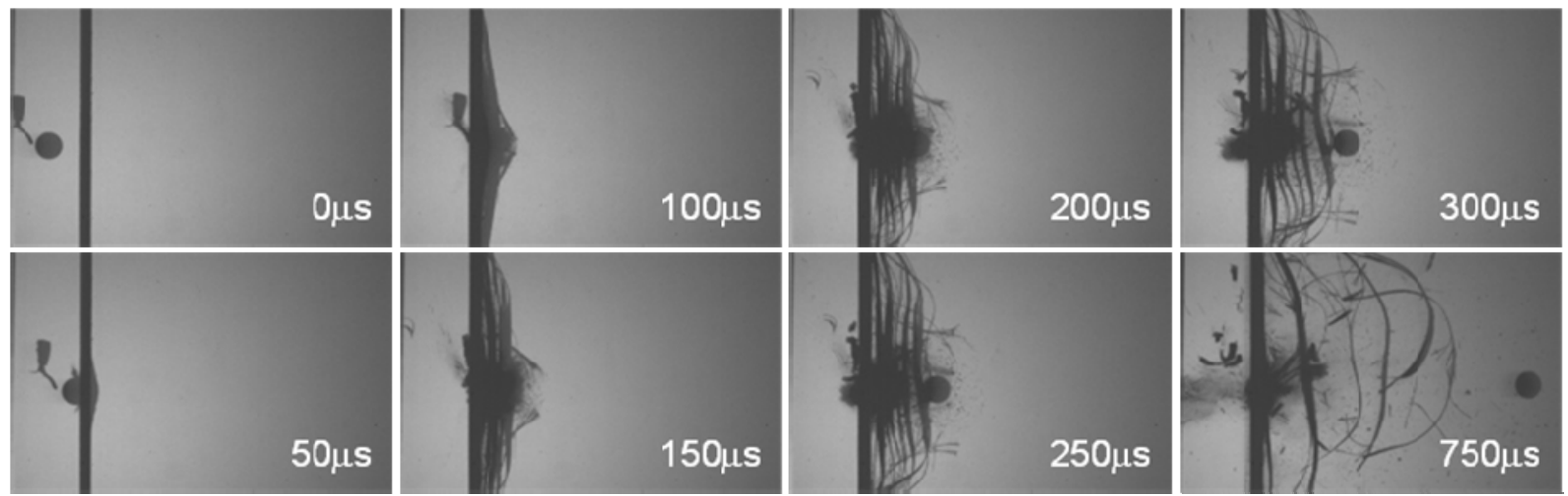

Figure 5 
Composite Structures 91 (2009) 103-109

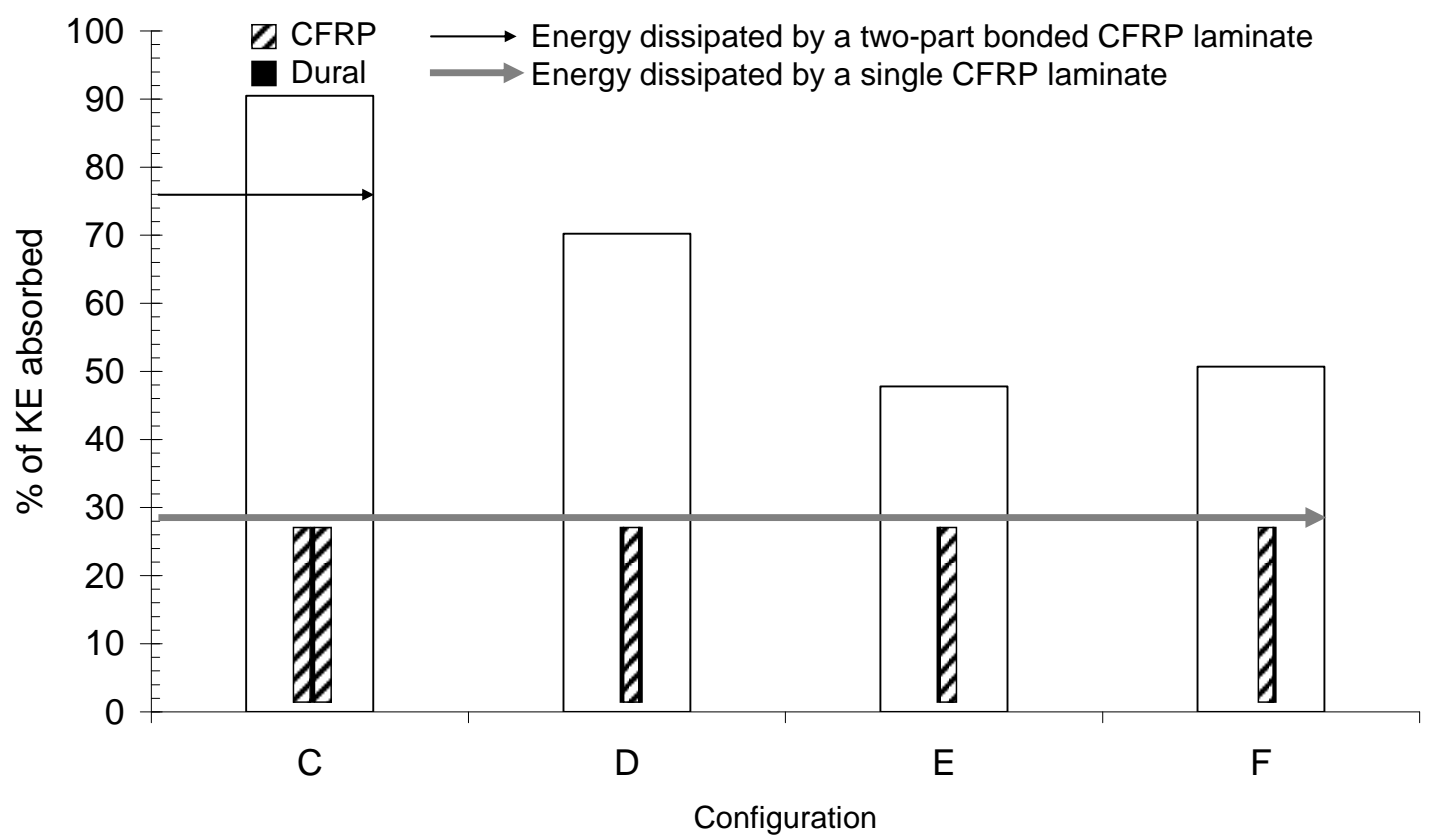

Figure 6 

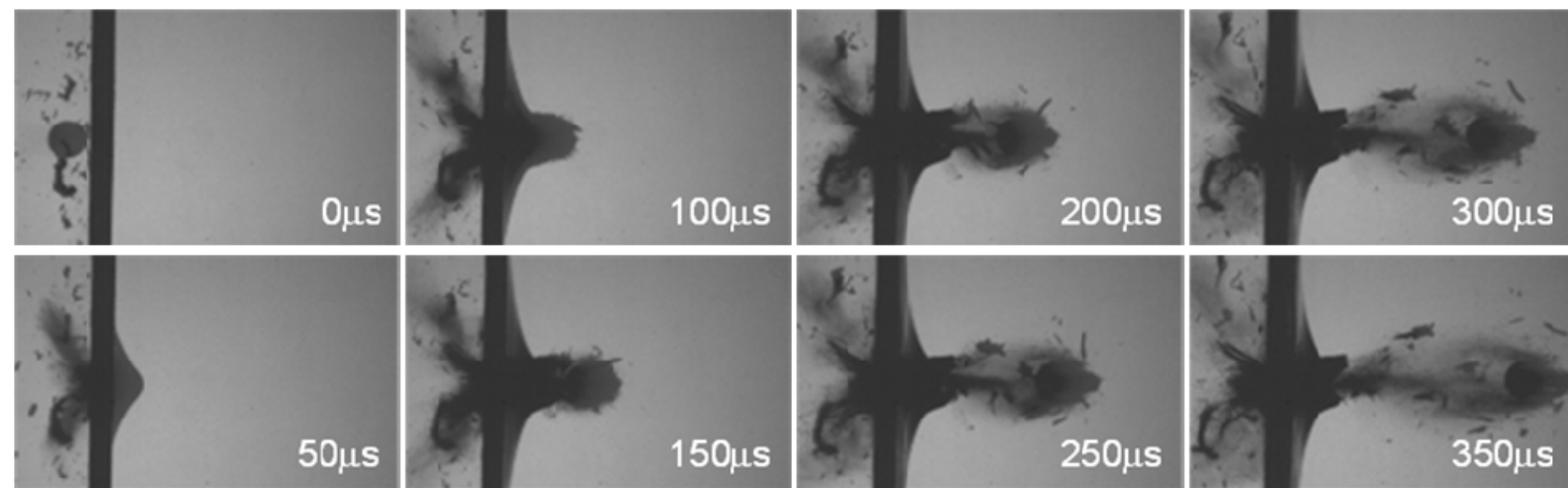

Figure 7 
Composite Structures 91 (2009) 103-109

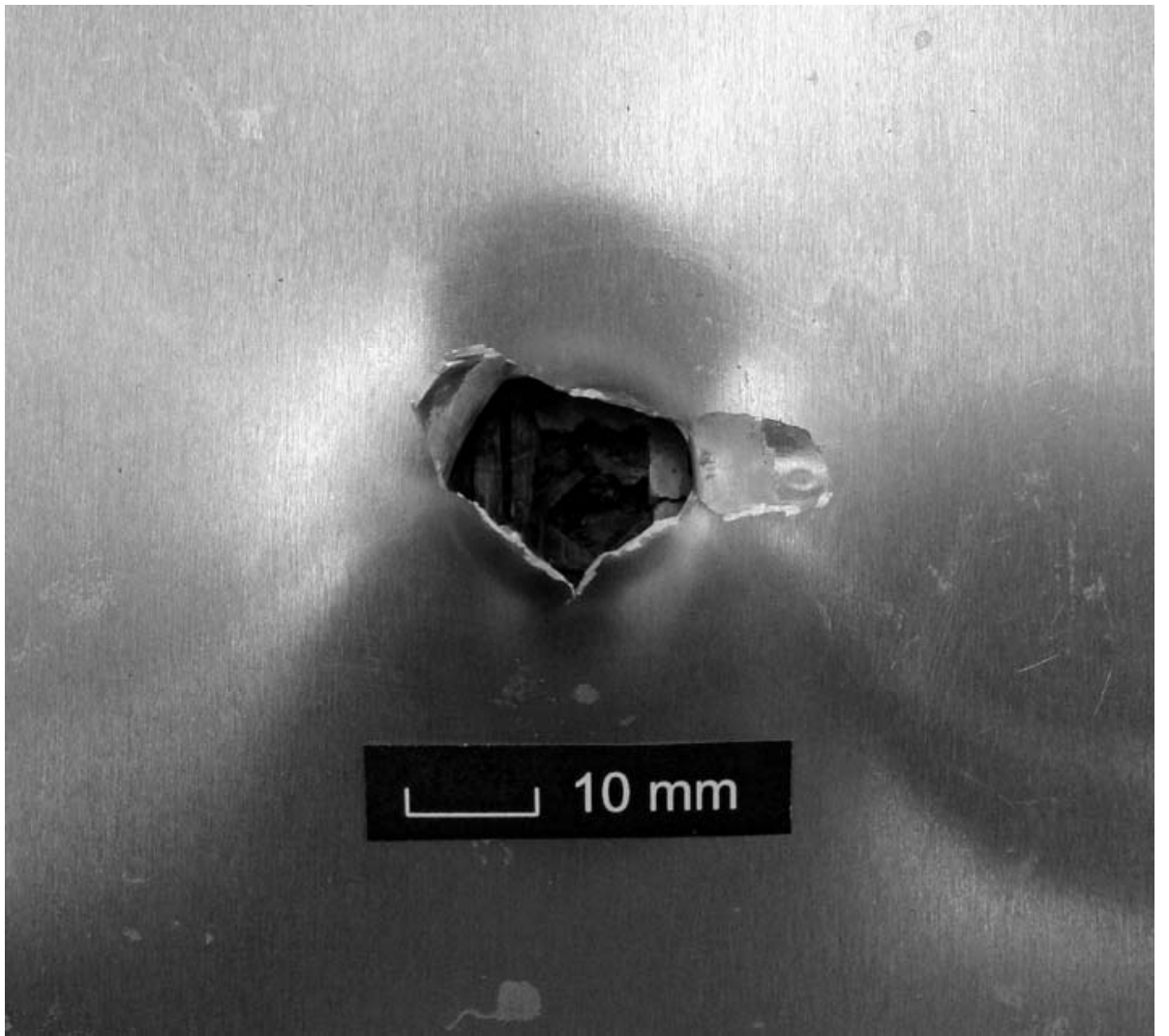

Figure 8 
Composite Structures 91 (2009) 103-109

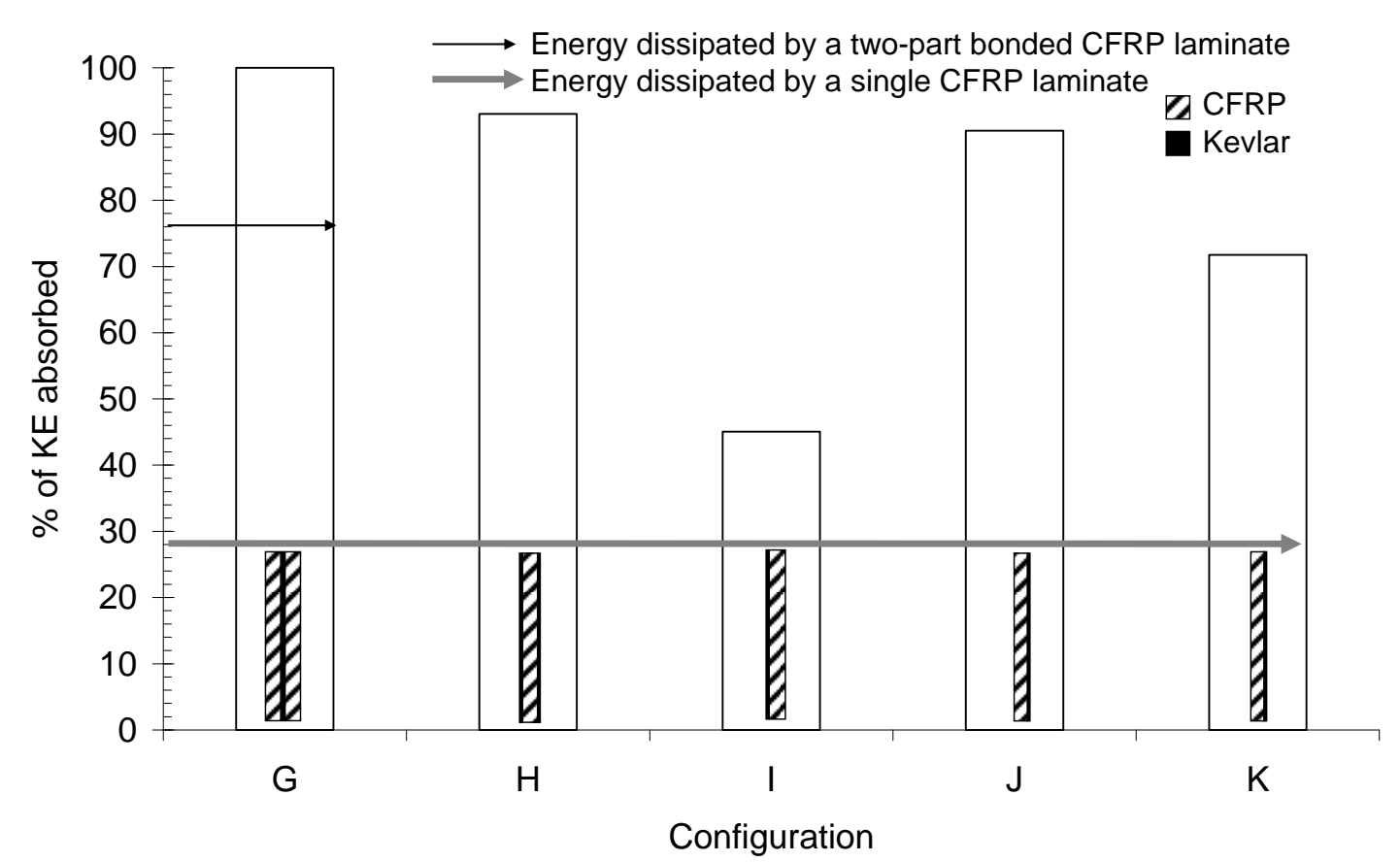

Figure 9 
Composite Structures 91 (2009) 103-109

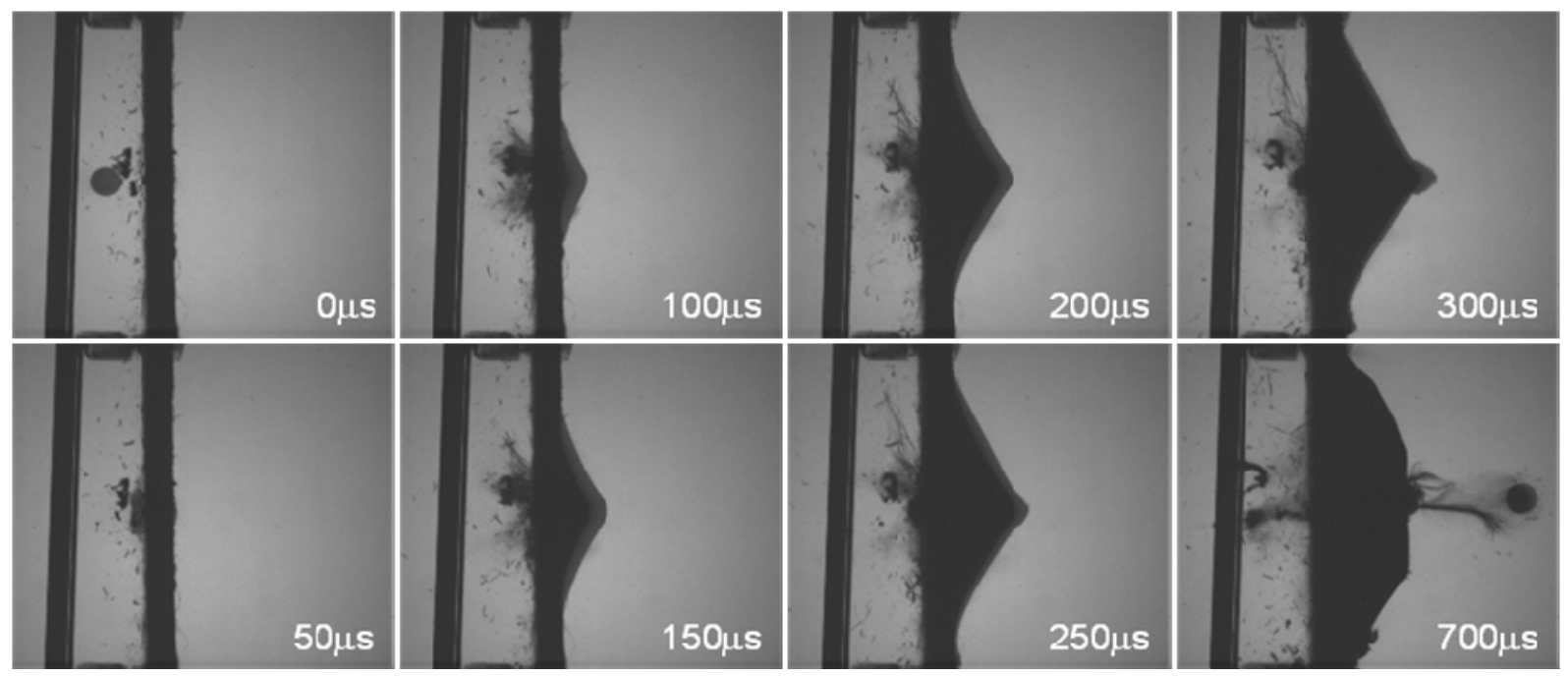

Figure 10 
Composite Structures 91 (2009) 103-109

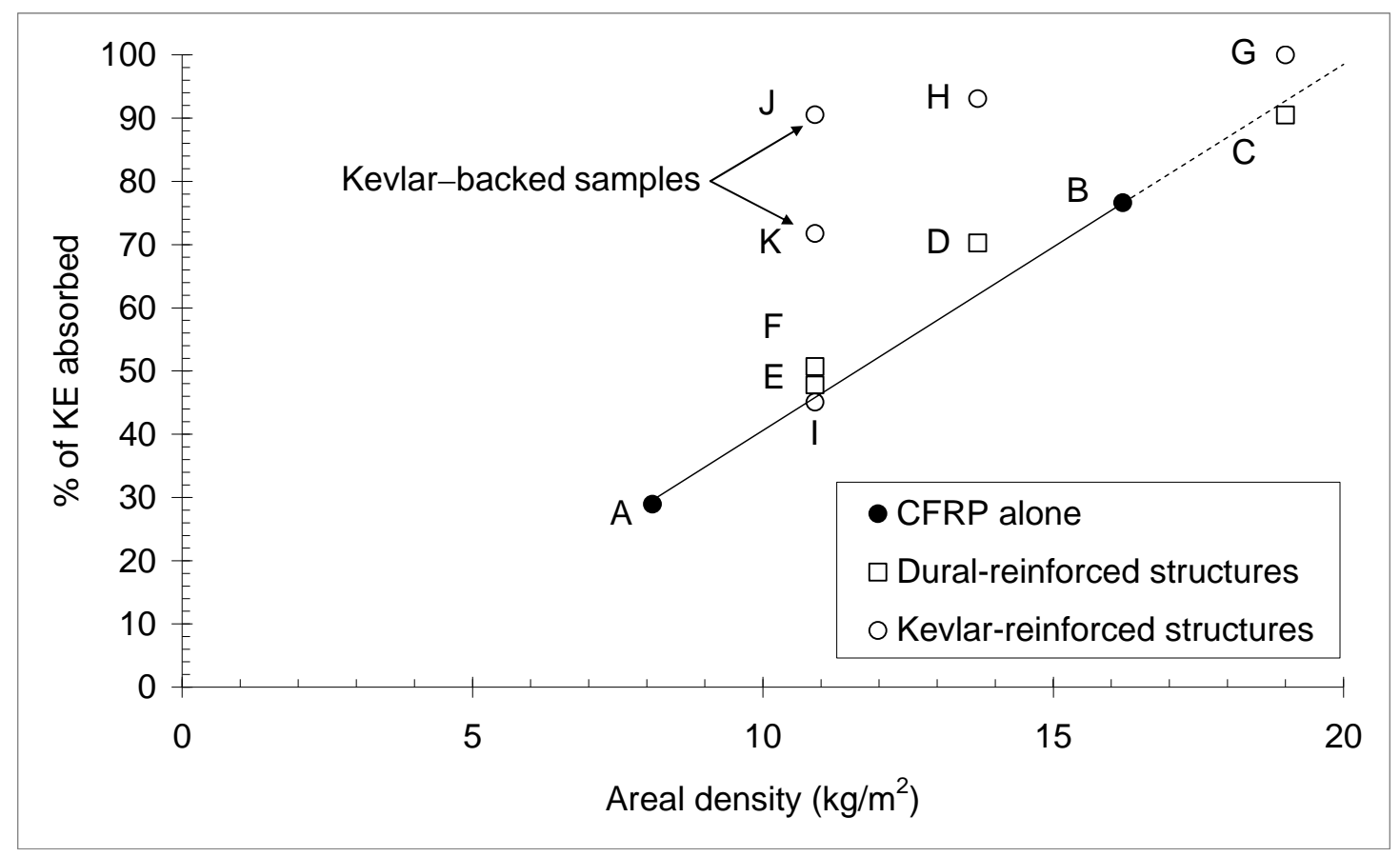

Figure 11 